\title{
Anti-tissue factor pathway inhibitor activity in patients with primary antiphospholipid syndrome
}

\author{
Murray J. Adams, Siobhán Donohoe, Ian J. Mackie and Samuel J. Machin Haematology Department, \\ University College London, London, UK
}

Received 19 November 2000; accepted for publication 16 April 2001

\begin{abstract}
Summary. The association between antiphospholipid antibodies and an increased risk of thrombosis in antiphospholipid syndrome (aPS) patients is probably caused by numerous mechanisms, including the effects of antibodies to phospholipid-binding proteins such as $\beta_{2}$-glycoprotein I and prothrombin. In this study, we investigated the inhibition of tissue factor pathway inhibitor (TFPI) in 33 patients with primary antiphospholipid syndrome (PAPS). TFPI was measured in PAPS patients using an amidolytic assay, dependent on the generation of activated factor $\mathrm{X}$ (Fxa), and this was compared with 55 healthy subjects. Functional levels of TFPI (mean \pm SD) were significantly lower in PAPS patients $(0.89 \pm 0.37 \mathrm{U} / \mathrm{ml})$ than the control group $(1 \cdot 05 \pm 0 \cdot 15 \mathrm{U} / \mathrm{ml})(P=0 \cdot 02)$. The difference was caused by a subset of five patients who had TFPI levels below the lower $99 \%$ confidence interval of the
\end{abstract}

normal reference range, representing increased FXa generation in the assay system. IgG fractions were isolated from these five patients and five control subjects, then incorporated into normal plasma to measure FXa generation in the TFPI assay system. FXa generation was increased when polyclonal rabbit anti-human TFPI IgG $(P<0 \cdot 0001)$ or PAPS IgG $(P=0 \cdot 0001)$ were added to normal plasma, demonstrating inhibition of TFPI. The apparent anti-TFPI activity demonstrated in the five subjects with PAPS in this study may represent a significant new mechanism for thrombosis in patients with aPS, as it implies that increased tissue factor FVIIa-mediated thrombin generation might occur.

Keywords: TFPI, antiphospholipid syndrome, anti-TFPI activity, factor Xa, thrombosis.
The antiphospholipid syndrome (aPS) is defined as the association of circulating autoimmune antiphospholipid antibodies (aPL) with arterial or venous thrombosis, recurrent fetal loss or thrombocytopenia (Hughes et al, 1986; Harris et al, 1987; Love \& Santoro, 1990; Wilson et al, 1999). aPL are directed against phospholipid-binding proteins including $\beta_{2}$ glycoprotein $\left(\beta_{2} \mathrm{GPI}\right)$ and prothrombin, and include lupus anticoagulant (LA) and anticardiolipin antibodies (aCL) (McNeil et al, 1990). Other, as yet unidentified, target antigens may be involved in aPS, and could include components of the tissue factor (TF) pathway of coagulation. Recent evidence suggests that upregulation of the TF pathway may be important in contributing to the hypercoagulability seen in aPS (Amengual et al, 1998). Reports by Adams et al (1995) who described decreased tissue factor pathway inhibitor (TFPI) activity in patients with lupus anticoagulants, and Salemink et al (2000) who reported enhanced FXa generation in three aPS patients in the presence of $\beta_{2} \mathrm{GPI}$, antibodies to $\beta_{2}$ GPI and TFPI, support this evidence.

Correspondence: Dr Murray Adams, School of Biomedical Sciences, Curtin University of Technology, GPO Box U 1987, Perth, WA 6845, Australia. E-mail: m.adams@curtin.edu.au
TFPI regulates the initiation of the tissue factor pathway by forming a quaternary complex (TF-FVIIa-FXa-TFPI) after the exposure of TF to the circulation (Broze et al, 1988). Upregulation of the TF pathway could potentially be caused by decreased TFPI activity or by an antibody to TFPI, contributing to the hypercoagulability in patients with aPS. In this paper, we report the presence of anti-TFPI activity in five subjects with primary antiphospholipid syndrome (PAPS), which could contribute to the thrombotic events in these patients.

\section{PATIENTS AND METHODS}

\section{Patients and samples}

Venous blood was collected with minimal stasis from 33 well characterized subjects with PAPS (Exner et al, 1991; Greaves et al, 2000). Blood was collected into empty tubes for the preparation of serum, or Vacutainers (Becton Dickinson, Oxford, UK) containing $0 \cdot 105 \mathrm{~mol} / \mathrm{l}$ tri-sodium citrate. Plasma was prepared by centrifuging at $2000 \mathrm{~g}$ for $15 \mathrm{~min}$ at room temperature. The plasma was separated and centrifuged again to ensure platelet depletion. Serum 
and double-spun plasma samples were stored in aliquots at $-70^{\circ} \mathrm{C}$ until required.

\section{Antiphospholipid antibody testing}

Lupus anticoagulant. LA was detected according to standard criteria (Greaves et al, 2000) using a commercial kit for the dilute Russell's Viper Venom Time, with a platelet neutralization procedure (Unicorn Diagnostics, London, $\mathrm{UK})$.

Anticardiolipin antibodies. IgG and IgM antibodies to cardiolipin were measured in serum samples using an enzyme-linked immunosorbent assay (ELISA) technique using microtitre plates (Polysorp, Nunc, Life Technologies, Paisley, UK) coated with cardiolipin (bovine heart, SigmaAldrich, Poole, UK). Assays were standardized using standard sera calibrated against the appropriate International Reference Material (Harris \& Hughes, 1987).

Anti- $\beta_{2} 2$ GPI antibodies. Anti- $\beta_{2}$ GPI IgG was measured by ELISA, using a commercial kit (Diastat anti $\beta_{2}$ GPI, AxisShield Diagnostics, Dundee, UK) based on a method previously developed in our laboratory (McNally et al, $1995)$. Anti- $\beta_{2}$ GPI IgM was assayed by an adaptation of the IgG kit components to accommodate the detection of $\operatorname{IgM}$ antibodies by using a $\mu$-specific conjugated secondary antibody. Assays were standardized using serum with a known high concentration of antibody.

Antiprothrombin antibodies. Antiprothrombin IgG and IgM were analysed by ELISA using $\mu$-irradiated microtitre plates (Maxisorp, Nunc, Life Technologies, Paisley, UK) coated overnight at $4^{\circ} \mathrm{C}$ with $10 \mu \mathrm{g} / \mathrm{ml}$ human prothrombin (Enzyme Research Laboratories, Swansea, UK) in phosphate-buffered saline (PBS) $(0.01 \mathrm{~mol} / \mathrm{l}$ phosphate, $0 \cdot 145 \mathrm{~mol} / \mathrm{l} \mathrm{NaCl}, \mathrm{pH} 7 \cdot 2$ ). Blocking was performed using PBS containing $0 \cdot 1 \%$ Tween 20 and $1 \%$ bovine serum albumin (BSA; Sigma-Aldrich, Poole, UK) for $1 \mathrm{~h}$ at room temperature. Plates were then washed once using PBS containing $0 \cdot 1 \%$ Tween 20 . A standard curve was prepared from reference plasma with a known high-aPT activity. Test samples were diluted 1:50 in PBS containing $0 \cdot 1 \%$ Tween 20 and $1 \%$ BSA. Next, $100 \mu \mathrm{l}$ of standard or test was added to duplicate wells for $1 \mathrm{~h}$ at room temperature. After three washes, $100 \mu \mathrm{l}$ of alkaline phosphatase-conjugated antihuman IgG or IgM was added for $1 \mathrm{~h}$. p-Nitrophenyl phosphate (100 $\mu \mathrm{l}$; Sigma-Aldrich, Poole, UK) in diethanolamine buffer $(\mathrm{pH} 9.8)$ was added and incubated at $37^{\circ} \mathrm{C}$ for colour development, which was stopped using $3 \mathrm{~mol} / \mathrm{l}$ $\mathrm{NaOH}$, and the absorbance read at $405 \mathrm{~nm}$.

All assays were validated by the inclusion of internal quality control samples of known activity. The cut-off point for the upper limit of normal was determined as the geometric mean $+95 \%$ Confidence Interval (CI) of values obtained in at least 30 apparently healthy adults.

\section{TFPI activity assay}

TFPI was measured using an amidolytic assay based on the method of Sandset et al (1987). Briefly, $25 \mu \mathrm{l}$ of diluted test or standard plasma was incubated with $100 \mu \mathrm{l}$ of reaction mixture containing equal amounts of recombinant $\mathrm{TF}$ (diluted 1/40) (Innovin, Dade Behring, Marburg, Germany),
0.013 U/ml FVII (Sigma-Aldrich,), 0.03 U/ml FX (Enzyme Research Laboratories) and $0.075 \mathrm{~mol} / \mathrm{l} \mathrm{CaCl}_{2}$, in flatbottomed microtitre plates (Alpha Laboratories, Eastleigh, UK). After incubation for $10 \mathrm{~min}$ at $37^{\circ} \mathrm{C}, 50 \mu \mathrm{l}$ of substrate mixture containing FX $(0.6 \mathrm{U} / \mathrm{ml})$ and an amidolytic substrate for FXa (S-2222, $2.7 \mathrm{mmol} / \mathrm{l}$; Chromogenix, Mölndal, Sweden) was added and incubated at $37^{\circ} \mathrm{C}$ for a further $30 \mathrm{~min}$. The reaction was stopped by the addition of $50 \mu \mathrm{l}$ of $50 \%$ acetic acid. The TFPI activity assay was standardized using Immuno Reference Plasma 100\% (Technoclone, Vienna, Austria). Results were derived from the mean of duplicate tests for all assays. The reference range was defined as the mean \pm 3 standard deviations.

\section{Protein G chromatography}

The IgG fraction was isolated from plasma by affinity purification on a Protein G column according to the manufacturer's instructions (Pharmacia Biotech, St Albans, UK). Samples were diluted 1 in 5 in PBS pH 7.4 and applied to a pre-equilibrated Protein G column. Bound IgG was eluted with glycine buffer, $\mathrm{pH} 2 \cdot 8$ and collected in $4 \mathrm{ml}$ fractions containing $0.6 \mathrm{ml} 1.0 \mathrm{~mol} / \mathrm{l}$ Tris. Fractions containing protein were pooled, dialysed to PBS and concentrated using an Amicon concentrator and a PM30 membrane. The protein concentration was determined by measuring the absorbance with a $1 \mathrm{~cm}$ light path and an extinction coefficient of $\mathrm{E} 1 \%, 1 \mathrm{~cm}=13 \cdot 6$, aliquoted and stored at $-70^{\circ} \mathrm{C}$.

\section{IgG mixing studies}

IgG fractions were isolated from the five PAPS subjects with increased FXa activity in the functional TFPI assay, and five normal controls. The fractions were mixed with normal plasma for $30 \mathrm{~min}$ at $37^{\circ} \mathrm{C}$ to a final concentration of $10 \mu \mathrm{g} / \mathrm{ml}$ and then assessed for functional TFPI activity. A rabbit anti-human polyclonal TFPI antibody (American Diagnostica, Greenwich, USA) was used in this system as a control to determine loss of TFPI activity in the normal plasma.

\section{Statistical analysis}

Between-group differences in functional TFPI were analysed using the student's two tailed $t$-test for unpaired data. $P$ values $<0.05$ were considered statistically significant.

\section{RESULTS}

Patients - clinical and laboratory details

Patients in this study were well characterized and did not have acute ongoing thrombotic events. These included 25 female and 8 male patients, mean age $47 \cdot 8 \pm 14 \cdot 4$ years (range 25-74 years). Twenty-six (79\%) patients had a clinical history of thrombosis (58\% venous; $21 \%$ arterial), $20(61 \%)$ were unequivocally LA-positive, 20 (61\%) had anti- $\beta_{2}$ GPI IgG/M antibodies, 16 (48\%) antiprothrombin IgG/M antibodies and 25 (76\%) anticardiolipin IgG/M antibodies. 


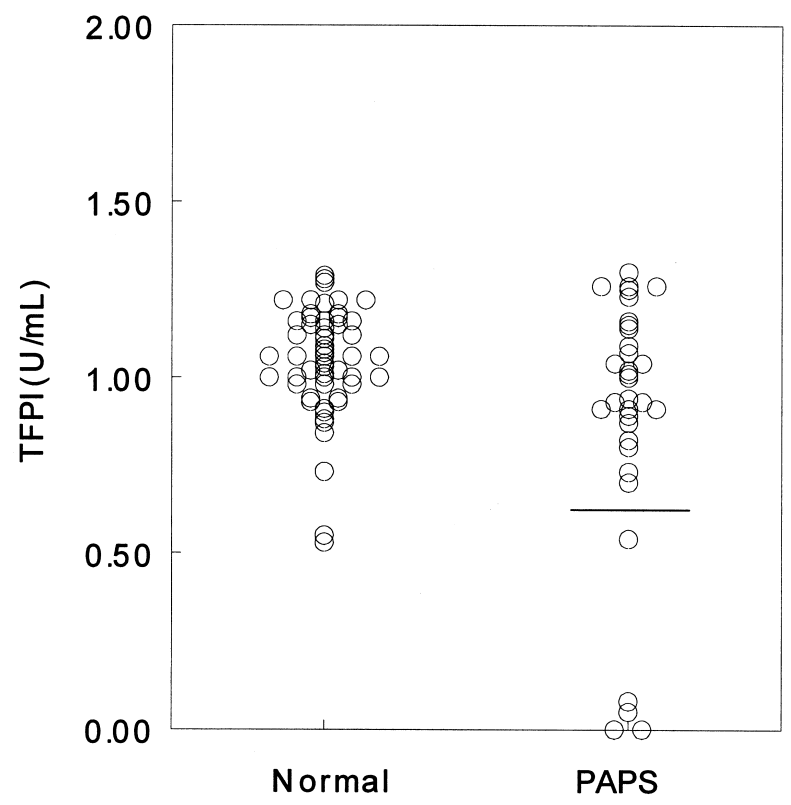

Fig 1. Functional TFPI in normal and PAPS subjects. Bar indicates lower $99 \%$ confidence interval of the normal reference range.

\section{TFPI levels}

The laboratory normal range for the functional TFPI assay was established using plasma from 55 healthy subjects ( 37 men, 18 women; mean age $=44 \cdot 2$ years) with no apparent haemostatic abnormality. The reference range was $0 \cdot 60-$ $1.50 \mathrm{U} / \mathrm{ml} \quad($ mean $=1.05 \mathrm{U} / \mathrm{ml} ; \quad$ standard deviation $=0 \cdot 15 \mathrm{U} / \mathrm{ml})($ Fig 1$)$.

Mean functional TFPI levels were $0.89 \pm 0.37 \mathrm{U} / \mathrm{ml}$ in 33 subjects with PAPS, which was significantly lower than levels in the normal subjects $(P=0 \cdot 02)$ (Fig 1$)$. The lower functional TFPI in the subject group was caused by a subpopulation of samples $(n=5)$, which generated increased FXa activity (below the lower 99\% confidence interval of the reference range). Three of these patients were receiving warfarin and aspirin, one was receiving aspirin only and one was receiving warfarin only as part of thromboprophylaxis because of previous events. No patient received heparin as part of their treatment.

Table I summarizes the major clinical and laboratory details of the five patients that demonstrated increased FXa activity in the functional assay for TFPI.

\section{TFPI inhibition}

TFPI activity in normal plasma was $100 \%$ inhibited after $30 \mathrm{~min}$ at $37^{\circ} \mathrm{C}$ by the addition of a polyclonal rabbit antihuman TFPI antibody $(10 \mu \mathrm{g} / \mathrm{ml})$. When the IgG fractions from the five selected patients was mixed with normal plasma, the mean TFPI activity was reduced from $0.99 \mathrm{U} / \mathrm{ml}$ to $0.72 \mathrm{U} / \mathrm{ml}(P=0.0001)$ (Fig 2). In each case, this represented a reduction of greater than $25 \%$ TFPI activity, and the effect was demonstrated on two separate occasions. When IgG $(0-20 \mu \mathrm{g} / \mathrm{ml})$ from one of the five PAPS subjects with low TFPI activity was added to normal plasma, TFPI activity was reduced in a concentrationdependent manner (Fig 3). Control IgG (final concentration $=10 \mu \mathrm{g} / \mathrm{ml}$ ) collected from five normal subjects demonstrated less than $1 \%$ reduction $(0.98 \mathrm{U} / \mathrm{ml})$ in TFPI activity when mixed with normal plasma.

\section{DISCUSSION}

There have been varying reports in the literature on TFPI levels in patients with aPS. TFPI antigen levels have been reported to be both higher (Amengual et al, 1998; Wakita et al, 1999), and lower (Kiraz et al, 1999), compared with the control groups. Although these variations have yet to be

Table I. Comparison of laboratory characteristics of PAPS subjects with normal $(n=28)$ and decreased $(n=5)$ TFPI activity in the functional assay for TFPI.

\begin{tabular}{lcc}
\hline & $\begin{array}{l}\text { Normal TFPI activity } \\
(n=28)\end{array}$ & $\begin{array}{l}\text { Decreased TFPI activity } \\
(n=5)\end{array}$ \\
\hline PAPS subjects & $6: 22$ & $3: 2$ \\
Sex (M:F) & $3(11)$ & $4(80)$ \\
Arterial thrombosis & $19(68)$ & $0(0)$ \\
Venous thrombosis & $14(50)$ & $4(80)$ \\
$\uparrow$ Anti- $\beta_{2}$ GPI & $9(32)$ & $1(20)$ \\
IgG & & $1(20)$ \\
IgM & $7(25)$ & $5(100)$ \\
$\uparrow$ Antiprothrombin & $23(82)$ & $2(40)$ \\
IgG & $20(71)$ & $3(60)$ \\
IgM & $8(29)$ & $3(60)$ \\
Anticardiolipin & $17(61)$ & $0 \cdot 13 \pm 0 \cdot 23$ \\
IgG & $1 \cdot 05 \pm 0 \cdot 17$ & \\
LupM & & \\
TFPI (U/ml) & & \\
\hline
\end{tabular}

Percentages are given in parenthesis. 


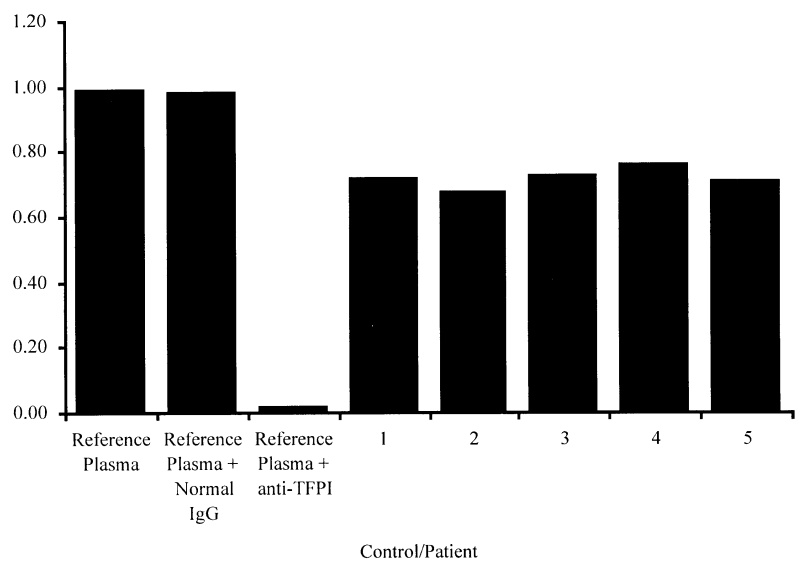

Fig 2. Functional TFPI levels in normal plasma with the incorporation of the IgG fraction from five patients with PAPS. Normal plasma $=0.99 \mathrm{U} / \mathrm{ml}$. Normal plasma + normal $\operatorname{IgG}=0.98 \mathrm{U} / \mathrm{ml}$. Normal plasma + anti-TFPI $=0 \cdot 02 \mathrm{U} / \mathrm{ml}$. Columns $1-5$ represent functional TFPI activity in normal plasma mixed with IgG from patients with PAPS (mean $=0 \cdot 72 \mathrm{U} / \mathrm{ml} ; P=0 \cdot 02$ ).

explained, it is feasible that an upregulation of coagulation, with increased levels of both TFPI and TF, could contribute to thrombosis in patients with aPS. Alternatively, if there is an imbalance between TF and TFPI levels, an increased risk of thrombosis may result owing to low levels of TFPI in the presence of normal or elevated TF.

Decreased TFPI activity in patients with LA has previously been demonstrated in an in vitro assay system (Adams et al, 1995; Adams \& Oostryck, 1997). The increased FXa generated in this system was abolished with the addition of excess amounts of thromboplastin. This inferred that LA preferentially targeted the phospholipid component of the assay, and was associated with decreased TFPI inhibition of TF-FVIIa-FXa. It was concluded that both the amount and source of thromboplastin used in this particular system affected the measurement of functional TFPI in patients with LA.

Subsequent reports have implicated the inhibition of TFPI anticoagulant activity by strong lupus anticoagulants (Jacobsen et al, 1999), and described enhanced FXa generation in three patients with aPS that was dependent on the presence of $\beta_{2}$ GPI, antibodies to $\beta_{2}$ GPI and TFPI (Salemink et al, 2000). Perhaps of most significance is a recent report on the presence of anti-TFPI antibodies in patients with aPS (Cakir et al, 2000). These antibodies were associated with stroke and arterial thrombosis, but not with other classical clinical features of aPS such as venous thrombosis.

In this study of a cohort of 33 PAPS patients, we report increased FXa generation (and, therefore, apparent TFPI reduction), as measured in a functional assay for TFPI. The statistical difference between PAPS patients and normal volunteers was caused by a small $(n=5)$ subset of the patient population. When these five patients were removed from the statistical analysis, there was no significant difference in functional TFPI levels. Four of the five patients

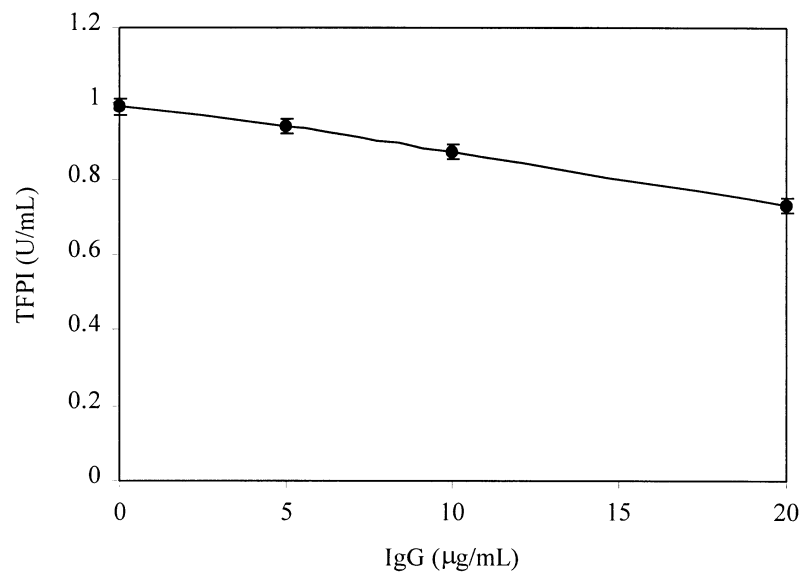

Fig 3. Effect of IgG concentration from a PAPS subject with low TFPI activity in normal plasma.

had a history of arterial disease, but none had venous thromboembolism, in keeping with the results of Cakir et al (2000).

We also demonstrated inhibition of TFPI activity after the addition of $\operatorname{IgG}$ fractions from the same five PAPS patients to normal plasma. The reduction in TFPI activity was consistently greater than $25 \%$, and was reproduced on two separate occasions. The increased generation of FXa is evidence of anti-TFPI activity in the IgG fraction from the selected PAPS patients.

The anti-TFPI activity demonstrated in this study is further evidence of an autoantibody to TFPI. Identification of a specific pathological anti-TFPI antibody will probably be confirmed with continued screening of IgG and/or IgM fractions from aPS patients, and the use of affinity chromatography for anti-TFPI. IgM anti-TFPI antibodies may be present in blood samples from PAPS patients and could explain some of the observed discrepancies between TFPI activity in patient plasma and the degree of inhibition of TFPI in mixing experiments of normal plasma and patient IgG. The presence of an anti-TFPI antibody in the plasma from patients with aPS patients would provide an explanation to the discrepant results of earlier reports (Adams et al, 1995; Adams \& Oostryck, 1997). Anti-TFPI antibodies may contribute towards the overall pathophysiological mechanisms of thrombosis in aPS patients. Indeed, in this study all five patients that demonstrated anti-TFPI activity also had a history of arterial thrombosis and/or stroke. Future work will be required to determine the incidence, clinical significance and the association with other antiphospholipid antibodies.

\section{REFERENCES}

Adams, M.J. \& Oostryck, R. (1997) Further investigations of lupus anticoagulant interference in a functional assay for tissue factor pathway inhibitor. Thrombosis Research, 87, 245-249.

Adams, M.J., Dunstan, R.A. \& Oostryck, R. (1995) Interference by lupus anticoagulant in a functional assay for tissue factor pathway inhibitor. Thrombosis Research, 80, 435-550. 
Amengual, O., Atsumi, T., Khamashta, M.A. \& Hughes, G.R. (1998) The role of the tissue factor pathway in the hypercoagulable state in patients with the antiphospholipid syndrome. Thrombosis and Haemostasis, 79, 276-281.

Broze, G.J., Warren, L.A., Novotny, W.F., Higuchi, D.A., Girard, J.J. \& Miletich, J.P. (1988) The lipoprotein-associated coagulation inhibitor that inhibits the factor VII-tissue factor complex also inhibits factor Xa: insight into its possible mechanism of action. Blood, 71, 335-343.

Cakir, B., Arnett, F.C. \& Roubey, R.A.S. (2000) Autoantibodies to tissue factor pathway inhibitor (TFPI) are associated with arterial thrombosis/stroke. Journal of Autoimmunity, 15, A11(Abstract).

Exner, T., Triplett, D.A., Taberner, D. \& Machin, S.J. (1991) Guidelines for testing and revised criteria for lupus anticoagulants. Thrombosis and Haemostasis, 65, 320-322.

Greaves, M., Cohen, H., Machin, S.J. \& Mackie, I.J. (2000) Guidelines on the investigation and management of the antiphospholipid syndrome. British Journal of Haematology, 109, 704-715.

Harris, E.N. \& Hughes, G.R. (1987) Standardising the anticardiolipin antibody test. Lancet., 1, 277.

Harris, E.N., Baguley, E., Asherson, R.A. \& Hughes, G.R. (1987) Clinical and serological features of the 'antiphospholipid syndrome'. British Journal of Rheumatology, 26, 19.

Hughes, G.R., Harris, N.N. \& Gharavi, A.E. (1986) The anticardiolipin syndrome. Journal of Rheumatology, 13, 486-489.

Jacobsen, E.M., Sandset, P.M. \& Wisloff, F. (1999) Do antiphospholipid antibodies interfere with tissue factor pathway inhibitor? Thrombosis Research, 94, 213-220.

Kiraz, S., Ertenli, I., Benekli, M., Haznedaroglu, I.C., Calguneri, M., Celik, I., Apras, S. \& Kirazli, S. (1999) Clinical significance of hemostatic markers and thrombomodulin in systemic lupus erythematosus: evidence for a prothrombotic state. Lupus, 8, $737-741$.

Love, P.E. \& Santoro, S.A. (1990) Antiphospholipid antibodies:
Anti-TFPI Activity in PAPS Patients

anticardiolipin and the lupus anticoagulant in systemic lupus erythematosus (SLE) and in non-SLE disorders. Prevalence and clinical significance. Annals of Internal Medicine, 112, 682-698.

McNally, T., Mackie, I.J., Machin, S.J. \& Isenberg, D.A. (1995) Increased levels of beta 2-glycoprotein-I antigen and beta 2glycoprotein-I binding antibodies are associated with a history of thromboembolic complications in patients with SLE and primary antiphospholipid syndrome. British Journal of Rheumatology, 34, 1031-1036.

McNeil, H.P., Simpson, R.J., Chesterman, C.N. \& Krilis, S.A. (1990) Anti-phospholipid antibodies are directed against a complex antigen that includes a lipid-binding inhibitor of coagulation: beta 2-glycoprotein I (apoliporotein H). Proceedings of the National Academy of Sciences of the United States of America, 87, 41204114.

Salemink, I., Blezer, R., Willems, G.M., Galli, M., Bevers, E. \& Lindhout, T. (2000) Antibodies to $B_{2}$-glycoprotein-I associated with antiphospholipid syndrome suppress the inhibitory activity of tissue factor pathway inhibitor. Thrombosis and Haemostasis, 84, 653-656.

Sandset, P.M., Abildgaard, U. \& Pettersen, M. (1987) A sensitive assay of extrinsic coagulation pathway inhibitor (EPI) in plasma and plasma fractions. Thrombosis Research, 47, 389-400.

Wakita, Y., Wada, H., Nakase, T., Nakasaki, T., Shimura, M. Hiyoyama, K., Mori, Y., Gabazza, E.C., Nishikawa, M., Deguchi, K. \& Shiku, H. (1999) Aberrations of the tissue factor pathway in patients positive for lupus anticoagulant. Clinical and Applied Thrombosis and Haemostasis, 5, 10-15.

Wilson, W.A., Gharavi, A.E., Koike, T., Lockshin, M.D., Branch, D.W., Piette, J.C., Brey, R., Derksen, R., Harris, E.N., Hughes, G.R., Triplett, D.A. \& Khamashta, M.A. (1999) International consensus statement on preliminary classification criteria for definite antiphospholipid syndrome: report of an international workshop. Arthritis and Rheumatism, 42, 1309-1311. 